\title{
A emergência do direito da saúde
}

The emergence of health law

La emergencia del derecho a la salud

André Gonçalo Dias Pereira ${ }^{1}$

RESUMO: Este texto analisa as dificuldades de um léxico uniformizado em torno da área, da prática e da investigação jurídica em torno do Direito e da Saúde, gerando múltiplas designações (Direito Médico, da Medicina, Sanitário, Biodireito, etc.). Seguidamente, defende que o Direito da Saúde se desenvolveu como um ramo do saber jurídico autónomo, com um conjunto de princípios, métodos hermenêuticos, um objeto de análise específico e problemas próprios de organização judiciária. Salientando a importância das ciências vizinhas, como a Bioética, a Medicina Legal, a Economia da Saúde, o Autor defende que só um pensamento jurídico estruturado, com formação dogmática e histórica, com capacidade de diálogo interdisciplinar, permitirá o desenvolvimento do Direito da Saúde, o que assume especial relevância no Século XXI, com a carência de água, com a hiperpopulação e a urbanização crescente da vida em sociedade.

Palavras-chave: Direito da saúde. Direito da Medicina. Direito Biomédico. Autonomia do Direito da Saúde. Princípios do Direito da Saúde.

ABSTRACT: This text analyzes the difficulties of a lexicon standardized around the area of practice and legal research concerning the interface between Law and Healthcare, generating multiple designations (Medical Law, Health Law, Biolaw, etc.). Next, it argues that Healthcare Law developed as a separate branch of knowledge with a set of legal principles, hermeneutical methods, a specific object of analysis and problems of judicial organization. Stressing the importance of neighboring sciences such as bioethics, the Legal Medicine, Health Economics, the author argues that only a structured legal thought, with a dogmatic and historical education, with capacity of interdisciplinary dialogue, will enable the development of Health Law, which is particularly relevant in the twenty-first century, with the lack of water, the global over-population challenge and the increasing urbanization of life in society.

Keywords: Health Law. Medical Law. Biomedical Law. Authonomy of Health Law. Principles of Health Law.

RESUMEN: este texto analiza las dificultades de un léxico estandarizado alrededor del área de práctica y la investigación legal en torno a la Ley y la Salud, lo que ha generado múltiples denominaciones (derecho médico, derecho sanitario, Bioderecho, etc.). A continuación, se argumenta que el Derecho de la Salud ha desarrollado como una rama del conocimiento legal separada con un conjunto de principios, métodos hermenéuticos, un objeto específico de análisis y problemas de organización judicial. Destacando la

\footnotetext{
${ }^{1}$ Professor da Faculdade de Direito da Universidade de Coimbra; Diretor do Centro de Direito Biomédico; membro da Comissão de Ética para a Investigação Clínica; Conselheiro do Conselho Nacional de Ética para as Ciências da Vida; Fundador da ALDIS - Associação Lusófona de Direito da Saúde.
} 
importancia de las ciencias vecinas tales como la bioética, la Medicina Legal, la Economía de la Salud, el autor sostiene que sólo un pensamiento jurídico estructurado, con una formación dogmática e histórica, con capacidad de diálogo interdisciplinario, permitirá el desarrollo del derecho sanitario, que es particularmente relevante en el siglo XXI, con la falta de agua, el reto de la sobre-populación planetaria y el aumento de la urbanización de la vida en la sociedad.

Palabras Ilave: Derecho sanitário. Derecho médico. Derecho Biomédico.

\section{Introdução}

\section{A Autonomia do Direito da Medicina}

Vem-se afirmando, por todo o mundo, a emergência de um ramo autónomo do saber jurídico: o Direito da Saúde. Este saber é autónomo em duas vertentes: quer face a ciências extrajurídicas, tais como a Bioética a Ética Médica ou a Medicina Legal, quer no domínio jurídico, com a necessidade de ultrapassar as divisões tradicionais entre o Direito Civil, o Direito Penal e o Direito Público(1).

No que respeita à delimitação face aos domínios extrajurídicos, reconhecemos que a inter e transdisciplinaridade são fundamentais para quem almeje cultivar o Direito da Medicina (2); impõe-se - todavia - uma separação epistemológica dos diversos saberes. Esta distinção revela-se assaz sibilina, visto que algumas fontes do mesmo derivam do labor bioético lato sensu, tais como os Conselhos de Ética nacionais e internacionais. Todavia, os utensílios de que temos necessariamente que lançar mão são os instrumentos do Direito. A medicina, rectius, a atividade médica em interação com a pessoa humana, é o objeto desta ciência normativa. Por isso, estamos em crer que sem a Metodologia do Direito, a História do Direito, os conhecimentos prévios de Direito Privado, Direito Público e Direito Penal dificilmente se poderá compreender o subsistema do Direito da Medicina.

\section{Direito Médico, Direito da Medicina, Direito Biomédico, Direito da Saúde, Biodireito, Direito Sanitário}

Como é próprio de uma jovem área do saber, verifica-se alguma indefinição terminológica (3). Num primeiro momento, a expressão dominante era a de Direito Médico - na expressão alemã Arztrecht, na inglesa Medical Law ou na francesa droit médical. Este versava sobre as normas jurídicas relativas à relação médico-paciente (4). 
Esta definição revela-se muito curta. Por um lado, está fechada sobre a profissão do médico, quando a medicina moderna conta com uma panóplia de outras profissões de saúde (enfermeiros, farmacêuticos, técnicos de saúde, psicólogos, etc.). Mas ainda com esta abertura, este direito versava primacialmente sobre os Direitos e Deveres dos Doentes, a Responsabilidade Civil, Penal e Disciplinar. O foco da atenção estava nos sujeitos: no médico e outros profissionais de saúde e no doente/ paciente.

Num segundo momento foi-se afirmando a noção de Direito da Medicina (5), (6). Neste caso, o objeto seria a atividade médica (em sentido amplo), ou seja, o Direito da Medicina estuda a vida humana, nos seus diferentes estágios, e o seu contato com a Medicina. Donde este ramo do Direito versaria sobre a vida humana, desde antes do nascimento até depois da morte da pessoa humana, nos diferentes contatos que mantém com a atividade da medicina. Porque a biologia e outras ciências da vida têm vindo a ocupar um lugar de destaque na atividade médica surgiu a feliz designação de Direito Biomédico.

A nomenclatura Direito Biomédico, contudo, não assume ainda a primazia visto que desfoca o cerne da problemática deste ramo do direito: a pessoa humana na relação com a (bio)medicina, remetendo - ao menos no plano semiológico - para dimensões mais tecnológicas ou científicas. A semântica forte de Biomedicina correlaciona-se fortemente com os aspetos da propriedade intelectual, da titularidade e exploração de bases de dados e biobancos, a investigação com células estaminais, por exemplo. Numa palavra: a "medicina de ponta". Ora, é na "medicina do quotidiano" (na feliz expressão de Guilherme de Oliveira) que radicam princípios e metodologias que permitirão a afirmação de um ramo do direito autónomo, a exigir consequências prático-normativas de concretização (7). ${ }^{2}$

Os desafios que a nova biotecnologia lança à pessoa humana são deveras relevantes e merecem uma investigação aprofundada (8) (9). Pensemos nos problemas da xenotransplantação, da manipulação genética, da investigação com embriões, da manipulação de tecidos e células humanas, da criação do ciborgue ou da clonagem de seres humanos ou mesmo da utilização do doping no desporto ou na vida profissional. Mas é na prestação de cuidados de saúde mais frequentes e mais comuns que se faz sentir a

\footnotetext{
2 No prefácio, propõe o Direito do Corpo Humano (droit du corps humain), como sendo um conjunto de regras, princípios e raciocínios que enquadram a atividade médica e biomédica e que permitem o controle das decisões tomadas pelos médicos e os cientistas, os quais envolvem frequentemente o conjunto da personalidade do indivíduo, para lá da dimensão corporal.
} 
necessidade de estudo jurídico, com vista a um aperfeiçoamento da legislação, a um olhar crítico sobre a jurisprudência e no lançar de humildes pedras no caminho que a doutrina portuguesa ainda tem que atravessar para um Direito da Medicina que contribua para a proteção da vida, da integridade física e psíquica da Pessoa Humana e outros direitos de personalidade, ao longo de toda a sua vida.

Em terceiro lugar, surge o Direito da Saúde. Este campo de estudos é mais amplo e inclui o Direito Médico e o Direito da Medicina, mas é mais abrangente. Expande os seus domínios ao Direito da Economia da Saúde, ao Direito Administrativo da Saúde, incluindo a regulação das profissões de saúde, bem como o Direito da Farmácia e do Medicamento e o Direito da Saúde Pública (10).

Assim, o Direito da Saúde versa sobre toda a área da saúde, numa perspetiva integrada. Regula, pois, uma atividade humana de elevadíssima relevância social e económica (11).

Erwin Deutsch aponta para a necessidade de estudar o Direito da Medicina, em conjunto com o Direito do Medicamento e o Direito dos Dispositivos Médicos, visto que todos funcionam como placas tectónicas: se um se move, mais cedo ou mais tarde, vai causar convulsões no outro ramo (12). E esse é o papel do Direito da Saúde: promover uma reflexão de nível macro sobre todo o fenômeno da saúde. Mas afirma-se então sobretudo como uma área do saber jurídico, mais ampla do que um verdadeiro ramo do direito autónomo, com uma dogmática específica.

Mais amplo ainda se afigura o Biodireito, conceito utilizado por Helena Pereira de Melo (13). Bios significa vida, pelo que as fronteiras entre o Direito da Saúde, o Direito Biomédico e o Direito Ambiental se afiguram pouco claras, donde - quer no plano dogmático, quer no plano pedagógico - temos dúvidas de que seja a melhor via para o desenvolvimento deste ramo do Direito.

Por seu turno, Oliveira (14) defende o conceito de Direito da Bioética, querendo referir-se ao Direito da Vida, incluindo a Ecologia. Para além de uma nomenclatura epistemologicamente defeituosa (pois confunde duas ordens normativas: o Direito e a Ética), fica por esclarecer que avanço jus-científico se consegue com a falta de preocupação com uma correta delimitação dogmática das figuras.

Finalmente, a terminologia Direito Sanitário que tem muita expressão no mundo hispânico e que encontra também acolhimento no Brasil e quase ignorada em Portugal e 
remete-nos - grosso modo - para o mesmo conteúdo que o Direito da Saúde, enquanto ramo muito amplo do conhecimento.

Existirá um quid que justifique uma diferente qualificação dos factos e uma metodologia de resolução dos problemas distinta, numa dogmática do Direito da Saúde ou Direito Sanitário?

Parece-nos que a resposta essa questão deve ser positiva.

O corpo do Direito da saúde consiste num conjunto de normas que versam ou que dirimem os conflitos de interesses juridicamente relevantes na relação entre o médico e o paciente, nos vários contatos entre a pessoa humana e o sistema médico e sanitário. $\mathrm{O}$ espírito seria um conjunto de princípios jurídicos, rectius, de princípios normativos específicos que irradiam soluções de normatividade justa na relação entre a pessoa humana e a atividade da prestação de saúde, em sentido amplo.

\section{O Papel da Ética Médica e da Deontologia Profissional no Direito da Medicina}

O Direito da Medicina não é um ramo do direito com um estatuto especial para médicos ou que visa conceder privilégios a estes profissionais. Antes pelo contrário, visa promover uma relação de confiança num encontro de autonomias partilhadas (15), (16) em que a cidadania esteja presente também nesses domínios da intimidade e do encontro em situação de vulnerabilidade dos pacientes.

Este é um ramo do direito em que as ligações à ética são muito fortes. Interessa salientar a importância que a deontologia profissional pode ter na responsabilidade civil.

A autorregulação dos médicos ou o direito profissional tem várias vantagens. Este Direito criado pelos próprios médicos tem a função de disciplinar os comportamentos, forma e desenvolve um ethos profissional. As normas infralegais, de acordo com o princípio da autorregulação e autoadministração das associações ou ordens profissionais, com maior proximidade às questões a regular, podem fazê-lo melhor que ao nível estadual, e gozam ainda de uma melhor aceitação. A ordem jurídica igualitária, relativamente estática, apenas deve intervir a partir de uma certa grandeza dos problemas, porque aí já a ética profissional não consegue preencher essa necessidade de regulamentação (17) Por outro lado, quanto melhor funcionar a regulamentação profissional, menos terá o direito da responsabilidade civil que intervir. Pelo contrário, se o direito profissional e disciplinar se 
revelar insuficiente, as normas gerais do direito estadual, em sede indemnizatória, estarão presentes para tutelar a situação (18).

A Democracia Representativa - enquanto meio de obtenção da volonté génerale rousseauniana neste específico microcosmos do Direito da Medicina - deveria ser desenvolvida, seja através do mais eficaz funcionamento dos colégios de especialidade e das sociedades científicas na criação de guidelines e protocolos, seja no diálogo com associações de doentes e destas com as comissões de ética, bem como com o legislador da República (19), sem nunca esquecer a arte da medicina se faz perante o doente concreto.

Em Portugal, o Código Deontológico da Ordem dos Médicos assume claramente a natureza de regulamento administrativo, tendo - após a sua discussão e aprovação pelos órgãos próprios da Ordem dos Médicos - sido publicado sob a forma de Regulamento $\mathrm{n}$.ำ 707/2016 (Regulamento de Deontologia Médica), de 21 de julho de 2016.(20) Esta solução, dissonante do que acontece com outras ordens profissionais, ${ }^{3}$ não pode significar uma menor dignidade ou importância da Deontologia emanada da Ordem dos Médicos. Esta tem, naturalmente, no domínio do Direito da Medicina um relevo substancial.

As normas do Código Deontológico devem ser interpretadas em conformidade com a Constituição; em segundo lugar, na medida em que uma norma do Código Deontológico viole os direitos fundamentais, deve ter-se por inválida; terceiro, se o Código estiver em desconformidade com a lei prevalece esta última, que tem maior dignidade formal, em razão da sua maior legitimidade político-democrática.

\footnotetext{
3 A deontologia dos profissionais de saúde ora se encontra sob a forma de Lei, de Decreto-Lei, de Regulamento ou mesmo ainda no mero domínio associativo-deontológico. Assim, o CDOM, como vimos, encontra-se no Regulamento $n .{ }^{\circ}$ 14/2009 (DR II. ${ }^{\text {a }}$ Série, 13 de janeiro); o Código Deontológico dos Médicos Dentistas também se encontra em Regulamento interno $n . .-2 / 99$ ( $D R$ - II. ․ㅡ Série, n.․ 143, de 22 de junho), alterado pelo Regulamento interno no 4/2006 (DR - II. a Série, n. ${ }^{-103}$, de 29 de maio); do mesmo modo, o Código Deontológico da Ordem dos Psicólogos Portugueses consta do Regulamento № 258/2011 (DR, II. ${ }^{\mathrm{a}}$ Série, de 20 de abril de 2011). Por seu turno, o Código Deontológico dos Farmacêuticos conta do Decreto-Lei n. - 288/2001, de 10 de novembro, que cria o Novo Estatuto da Ordem dos Farmacêuticos inclui Código Deontológico; também o Código Deontológico do Enfermeiro está inserido no Estatuto da Ordem dos Enfermeiros e republicado como anexo pela Lei $n$. ․ 111/2009, de 16 de setembro.Já o Código Deontológico dos Biólogos não se encontra em forma legal, o mesmo acontecendo no domínio dos Técnicos de Saúde. Aqui encontramos o Código Deontológico dos Técnicos de Radiologia/Técnicos de Radioterapia/Técnicos de Medicina Nuclear; o Código de Ética da Associação Portuguesa dos Técnicos de Análises Clínicas e Saúde Pública; o Código Deontológico da Associação Portuguesa de Higienistas Orais (1992); o Código Ético e Deontológico da Associação Portuguesa de Cardiopneumologistas (março de 2006); o Código Deontológico dos Audiologistas (junho de 2005) e a Carta Ética dos Técnicos de Farmácia (junho de 2006).
} 


\section{A Dogmática Jurídica do Direito da Saúde}

No plano das fontes, o Direito da Saúde mostra especificidades. Para além das normas internacionais e europeias assumirem uma grande importância, dada a internacionalização da ciência médica e do debate em torno do Direito Biomédico, no plano nacional não devemos atender apenas às tradicionais fontes legislativas, mas ainda às diferentes deontologias profissionais, aos pareceres das Comissões de Ética e à prática jurídica.

Em segundo lugar, estas normas apresentam uma estrutura reflexiva e organizada em torno de um campo de atuação social e jurídica. Trata-se de uma estrutura com diferentes níveis de atuação assente em três pilares que constituem um triângulo normativo.

No seu vértice superior, encontramos os Direitos, liberdades e garantias plasmados na Constituição da República; nos ângulos inferiores situam-se os Direitos de Personalidade (generosamente atípicos e abertos às evoluções da biomedicina, designadamente através da consagração do Direito Geral de Personalidade), de um lado, e o Direito Penal Médico, com a proteção tipificada, subsidiária e fragmentária de bens jurídicos fundamentais à conservação da sociedade politicamente organizada.

Todos os vértices deste triângulo mantêm uma relação dialética e sujeita à historicidade, mas a sua robustez permite erguer um edifício cujas traves-mestras serão: 0 Direito Civil da Medicina, o qual inclui os direitos e deveres dos pacientes e a reparação do "dano injusto". Assim, o direito ao tratamento de adequado ou de acordo com as leges artis; o direito à informação e ao consentimento; o direito ao sigilo profissional e o direito à não discriminação erguem um corpus normativo denso, robusto e seguro que permitirão sustentar o edifício do Direito da Medicina. Na densificação deste ramo do Direito, encontramos matérias como a PMA, a IVG, os Cuidados Paliativos, a Saúde Mental, a Proteção dos dados pessoais ou o acesso à informação de saúde, entre outras.

O Direito Civil ocupa, assim, um lugar decisivo nesta emergente área dogmática. Relembremos Paulo Cunha: "Cada gesto, cada silêncio, cada omissão - tudo é regulado pelo Direito Civil." (14), (20).

Se este é o corpus, em que consistirá o spiritus do direito médico? 
Três conceitos sintetizam o seu espírito: a específica solidariedade existencial que a concreta e íntima relação de cuidado-perigo (Faria Costa) médico-paciente postula e o intento de criar confiança (Guilherme de Oliveira).

Este lema de missão - advogado por Guilherme de Oliveira - visa a confiança na Medicina, confiança no Direito, confiança nos profissionais, confiança nos doentes: enfim, promover a melhoria dos cuidados de saúde através da humanização da relação e da consagração de direitos humanos fortes nesta relação de especial vulnerabilidade.

Vulnerabilidade por vezes dupla: o doente porque está enfermo e necessita de proteção; o médico porque tantas vezes não dispõe da solução, de uma varinha mágica, mas apenas de meios, de erráticos esforços e intencionadas tentativas, como bem traduz a noção da responsabilidade civil de obrigação de meios.

Isto implica que o Direito da Saúde será um sistema de parceria e não um sistema vertical/ hierarquizado. Ao contrário do Direito do Trabalho, não há subordinação jurídica entre os profissionais e os doentes e entre os profissionais de saúde entre si. Tem, contudo, semelhanças com o Direito do Consumidor (21):4 "há uma relação desequilibrada de uma parte, o doente, em situação de fragilidade; fragilidade que a Declaração Universal sobre Bioética e Direitos Humanos, da Unesco, de 2005, veio apelidar de vulnerabilidade" (art. 8.ํ) (22).

O Direito deve assim ser um contributo para o respeito dos grandes valores da comunidade: os Direitos Humanos, os quais se fundam no princípio da dignidade da pessoa humana. Subscrevemos, pois, as palavras de Céu Rueff quando afirma que o Direito da Medicina constitui "um sistema normativo que encontra a sua unidade conceptual na disciplina dos direitos humanos, sendo norteado e enformado pelos mesmos princípios jurídicos" (2).

Trazer à colação a terminologia e o ramo dos direitos humanos não é exagero nem uma degenerescência. Com efeito, Bobbio (23) chama a atenção para os direitos humanos de quarta geração, que contrariam todas as tentativas de subjugação do homem, nomeadamente através da manipulação do seu código genético.

\footnotetext{
${ }^{4}$ Separata dos Estudos de Direito do Consumidor, n. ${ }^{\circ}$ 7, 2005, p. 245 define o direito do consumidor como "conjunto de princípios e regras destinados à defesa do consumidor."
} 
Daqui derivam, na reflexão que fazemos e que coincide, grosso modo, com a Carta dos Direitos Fundamentais da União Europeia ${ }^{5}$ (art. 3.ำ 2), ${ }^{6}$ os seguintes princípios:

a) A proibição de usar o corpo e as suas partes como fonte de lucro;

b) $O$ respeito pelos direitos dos pacientes, designadamente: 0 direito ao consentimento, o direito à informação, o direito ao sigilo médico e o direito à não discriminação;

c) A proibição da eugenia.

\section{A proibição de usar o corpo e as suas partes como fonte de lucro}

Este princípio pode ser visto enquanto dimensão do princípio da não mercantilização de bens indisponíveis. Ensina o sociólogo de Coimbra, "bens indisponíveis são aqueles que não têm substituto" (24).

Também Gomes Canotilho e Vital Moreira (25) afirmam, respectivamente, que o princípio é o da indisponibilidade do próprio corpo e que este princípio tem como corolário lógico o "princípio da não venalidade o corpo" ou nas palavras de João Loureiro (26), o princípio da não venalização do corpo humano.

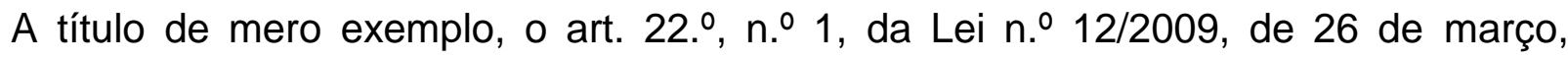
prescreve:

A dádiva de células e tecidos é voluntária, altruísta e solidária, não podendo haver, em circunstância alguma, lugar a qualquer compensação económica ou remuneração, quer para o dador quer para qualquer indivíduo ou entidade.

No mesmo sentido se determina a gratuitidade da doação de órgãos e tecidos (art. 5.ำ

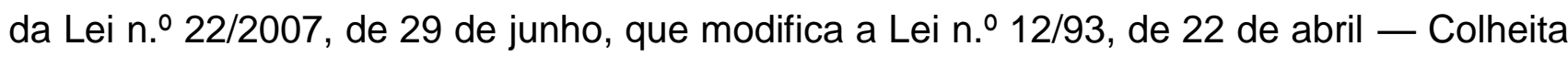
e transplante de órgãos, tecidos e células de origem humana), ${ }^{7}$ bem como a proibição da

\footnotetext{
${ }^{5}$ Com a entrada em vigor do Tratado de Lisboa, em dezembro de 2009, foi atribuído efeito jurídico vinculativo à CDFUE, tendo a mesma sido publicada no Jornal Oficial da União Europeia (JOUE) em 30 de março de $2010(2010 / C$ 83/02).

${ }^{6}$ Art. $3 .^{\circ}$, n. ${ }^{\circ}$ 2: "No domínio da medicina e da biologia, devem ser respeitados, designadamente: i. o consentimento livre e esclarecido da pessoa, nos termos da lei,; ii. A proibição das práticas eugénicas, nomeadamente das que têm por finalidade a seleção das pessoas, iii. A proibição de transformar o corpo humano ou as suas partes, enquanto tais, numa fonte de lucro,. iv. a proibição da clonagem reprodutiva dos seres humanos."

7 Subscrevemos, pois, as palavras de Gilles GENICOT, Le droit médical et biomédical, 2010, p. 53: "Un impératif est en permanence affirmé: l'autodetermination proclamée de l'individu est étroitement liée a la gratuité du prélèvement du matériel humain et, pourtant, à l'interdiction de tout profit, en raison du caractère
} 


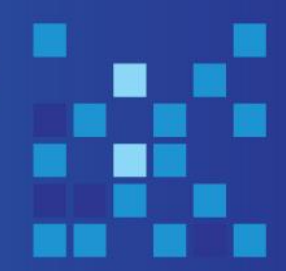

remuneração da participação em ensaios clínicos de medicamentos (art. 6, n.ำ1, al. h) da Lei n. ${ }^{\circ}$ 21/2014, de 16 de abril) ${ }^{8}$, bem como a proibição da maternidade de substituição no

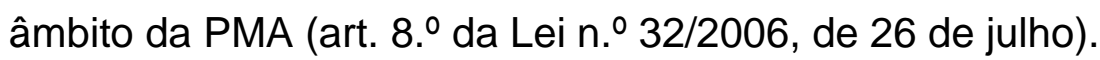

Estiveram em debate, na Assembleia da República dois Projetos de Lei sobre a PMA. O CNECV (Parecer n. ${ }^{\circ}$ 63/CNECV/2012) declarou acertadamente:

A gestação de substituição merece objeções, dúvidas ou, no mínimo, gera controvérsia relativamente a questões normalmente relacionadas com eventual mercantilização de uma área que se pretenderia imune a lógicas de mercado, exploração e instrumentalização das mulheres, comercialização e coisificação de bebés, degradação ou afetação do valor simbólico da gestação e da maternidade, para além das dificuldades em estabelecer uma regulação adequada das condições que devem enquadrar os negócios jurídicos em termos que atendam aos vários interesses em presença.

Recentemente, após um processo legislativo algo atribulado, que incluiu um veto do Presidente da República a que vimos apelidando de veto institucional ${ }^{9}$ (um tertium genus entre o veto político puro e o veto constitucional), a Assembleia da República aprovou o Decreto da Assembleia n. ${ }^{\circ}$ 27/XIII que "Regula o acesso à gestação de substituição, procedendo à terceira alteração à Lei n. ${ }^{\circ}$ 32/2006, de 26 de julho (procriação medicamente assistida)" que veio abrir a porta a um contrato de gestação de substituição necessariamente gratuito e controlado pelo CNPMA (Conselho Nacional de Procriação Medicamente Assistida).

Isto revela que o livre desenvolvimento da personalidade e o princípio de autodeterminação bioética se está a transformar em argumento fundamental na Bioética e no Biodireito lusos. Temos dúvidas de que a radicalização desse discurso seja o melhor caminho para a proteção da dignidade da pessoa humana. A técnica de gestação de substituição constitui uma certa reificação mais evidente do corpo da mulher. ${ }^{10} \mathrm{~A}$ mulher

extrapatrimonial du corps humain et de ses élements et produits. (...) II s'agit d'une limite au droit de disposer de son corps."

8 h) Não forem concedidos quaisquer incentivos ou benefícios financeiros, sem prejuízo do reembolso das despesas e do ressarcimento pelos prejuízos sofridos com a participação no estudo clínico.

9 Veto "institucional" na medida que o Presidente da república não vetou por razões de consciência, éticas ou políticas, mas porque entendeu que a aprovação feita em junho violava os dois Pareceres do Conselho Nacional de Ética para as Ciências da Vida e desconsiderava uma recomendação do Parlamento Europeu, documentos esses todos muito críticos ou restritivos da maternidade de substituição.

${ }^{10}$ Nas palavras do Relatório Warnock (1985), p. 45: "it is inconsistent with human dignity that a woman should use her uterus for financial profit". 


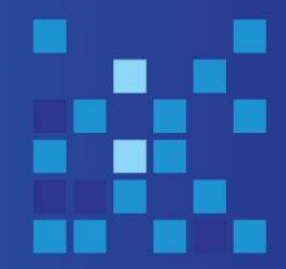

como instrumento, como uma máquina de criar bebês que no "prazo do cumprimento do contrato" será "entregue" aos pais, sob pena de... execução específica? Sanção pecuniária compulsória? Cláusula penal? Indemnização por danos?

Uma Constituição que "leve a sério" parafraseando Ronald Dworkin, (27) princípio da dignidade humana e o respeito pelo corpo e pela dignidade da mulher não deve ser cúmplice de tal degradação do ventre da mulher e do seu abdôme, enquanto objeto de negócios jurídicos exclusivamente patrimoniais...

Um discurso que parece tão moderno e libertador - o caso de paternidade gay através de técnicas de PMA - pode, de fato, trazer opressão, discriminação, humilhação e reificação do estatuto da Mulher e com ela do Ser Humano.

\section{O Direito à não discriminação}

O princípio da não discriminação assume no domínio da saúde uma grande importância. Alguns grupos de pessoas têm sido objeto de estudo e proteção jurídica mais atenta, como as pessoas que vivem com VIH e os sobreviventes de cãncer. Assume

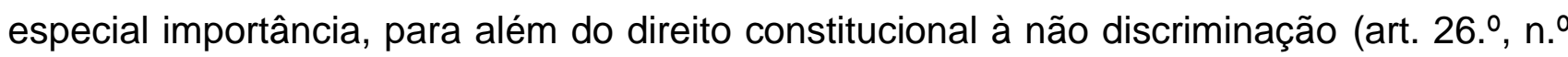
1, CRP como expressão do princípio da igualdade (art. 13. CRP; cf. ainda o art. $21 .^{\circ} \mathrm{da}$ Carta dos Direitos Fundamentais da União Europeia), a Lei n.. 46/2006, de 28 de agosto (Proíbe e pune a discriminação em razão da deficiência e da existência de risco agravado de saúde) e, no plano internacional, a Convenção de Nova lorque sobre Proteção de Pessoas com deficiência.

Destes princípios derivam as seguintes consequências:

O Direito da Saúde não deve ser um espaço de imposição de valores das maiorias, sejam maiorias éticas, sociológicas, religiosas ou outras, donde o direito à objeção de consciência e a existência de um direito médico laico, não confessional, são condições essenciais. Relembremos que a democracia é o respeito pelas minorias, pelo que um Direito da Saúde democrático ${ }^{11}$ deve seguir essa máxima.

\footnotetext{
11 A democracia nos cuidados de saúde - "la fondation d'une démocracie sanitarie - é também uma exigência da doutrina francesa, tendo a lei de 4 de março de 2002, com o reconhecimento da autonomia do paciente e o desenvolvimento do direito à informação e à participação no sistema de saúde sido um marco fundamental nesta direção - como afirma Benjamin PITCHO, Le statut juridique du patient, Bordeaux, Les Études Hospitalières, 2004, p. 548. Segundo este autor, a Organização Mundial de Saúde tem contribuído para este novo papel do paciente nos cuidados de saúde, desde logo com a Declaração de Alma-Ata de
} 
O Direito sanitário não deve ser um espaço de consolidação/ cristalização de desequilíbrios sociológicos. Assim, perante o normal desequilíbrio social e económico entre o prestador de saúde e a pessoa doente; considerando a vulnerabilidade especial de alguns pacientes perante os profissionais e a família, como os idosos e os doentes mentais; perante as fragilidades especiais dos adolescentes, dos toxicodependentes, dos portadores de doenças graves, o Direito deve afirmar-se como um ponto de reequilíbrio e de promoção dos direitos humanos das pessoas em estado de vulnerabilidade. O jurista deve estar ciente de que a família pode ser uma instituição de opressão e humilhação, como magistralmente é descrita pelo dramaturgo andaluz, Federico Garcia Lorca, em Bodas de Sangue. Vigora o princípio de interpretação em conformidade com a Constituição, em que pontifica o direito ao desenvolvimento da personalidade (art. 26.ำ CRP) e o princípio da proporcionalidade (art. 18. CRP).

Em terceiro lugar, o Direito da Saúde não deve ser um espaço de afrontamento e de crispação entre os diversos atores da saúde. O confronto entre as diversas classes profissionais na saúde é inevitável, como inevitável é o conflito: fonte primeira do próprio Direito!

Médicos, Enfermeiros, Farmacêuticos, Técnicos de Saúde, Assistentes operacionais, Economistas e Gestores da Saúde, Indústria farmacêutica têm naturalmente interesses conflituantes e contrapostos. Os conflitos interprofissionais devem ser regulados no âmbito do Direito Administrativo e do Direito do Trabalho: não no Direito da Medicina.

Os profissionais devem estar ao serviço da pessoa doente, em nome do princípio da solidariedade existencial, que assume aqui, mais uma vez, uma função reguladora.

Os doentes têm também interesses conflituantes com os financiadores, sejam os contribuintes (no sistema de Beveridge, com um Serviço Nacional de Saúde), sejam os

\footnotetext{
1978 que impõe aos Estados membros uma direção em matéria de política de saúde e procura a mobilização dos indivíduos no sentido da concretização do direito e do dever de saúde, recordando ainda a sua noção subjetiva e ampla de saúde ("saúde é um estado de pleno bem estar físico, psíquico e social" (OMS, 1947) e o seu ideal democrático dos Direitos do Homem, concebido como condição necessária para alcançar a sua missão.A démocracie sanitaire foi um dos motes da loi Kouchner (cf. Claude EVIN/ Bernard CHARLES/ JeanJacques DENIS, Rapport sur le Projet de loi no 3258 relatif aux droits des malades et à la qualité du système de santé, Assemblé Nationale, 2001); cf. ainda Emmanuel TERRIER, Déontologie médicale et droit, Bordeaux, Les Études Hospitalières, 2003.
} 
segurados (sistema de Bismarck ${ }^{12}$, de seguro obrigatório a cargo dos trabalhadores (e outros residentes). Esta altercação existe e existirá cada vez mais, devido ao aumento dos custos em saúde e a crise financeira dos Estados, mas o lugar próprio da sua regulação não é o Direito da Medicina, mas sim o Direito Constitucional, o Direito Fiscal, o Direito dos Seguros, o Direito da Segurança Social...

\section{Os desafios da autonomia do Direito da Saúde}

Vimos pela negativa o que o Direito da Medicina não deve ser. Vejamos agora a dogmática do Direito da medicina numa perspetiva positiva e, para tanto, responderemos às seguintes questões:

i. Qual a sua relação jurídica específica?

ii. Quais os problemas jurídicos-tipo dessa relação jurídica?

iii. Qual a justificação deste ramo do direito cuja autonomia procuramos afirmar?

iv. Quais as normas de interpretação jurídica e de integração de lacunas?

v. Que consequência poderá trazer para a organização judiciária esta colocação do problema? Será recomendável a existência de tribunais especializados?

A relação jurídica regulada é a relação entre o profissional de saúde (ou uma instituição) e a pessoa doente ou o paciente que procura serviços e tratamentos médicos terapêuticos ou não terapêuticos. ${ }^{13}$

Os problemas jurídicos-tipo desta relação jurídica são os que se prendem com o contato da pessoa humana, incluindo a fase pré-concepcional e o período post-mortem, com a atividade médica.

De jure condendo, defendemos uma regulação unitária, independentemente do local da prestação dos cuidados. Nesse sentido evoluiu a lei francesa de 4 de março de 2002 , consagrando um sistema de compensação da responsabilidade civil médica e da compensação por danos decorrentes da álea terapêutica e de infeções nosocomiais igual, seja para hospitais públicos, seja para hospitais privados.

\footnotetext{
12 "1881 became the year of social insurance on a national level: draft bills for disability and health insurance, workers' compensation and retirement benefits were either submitted to parliament or announced and supported by a message from the Kaiser."

13 O predomínio da medicina terapêutica está ultrapassado. Para além de uma panóplia de atos médicos em que o cidadão solicita, dentro de certos pressupostos e condicionalismos, uma intervenção (IVG, esterilização, cirurgia estética) há ainda todo o domínio da medicina preditiva, da medicina preventiva e da saúde no trabalho, na escola, no desporto... que conduzem a uma atividade médica de grande amplitude.
} 
Por outro lado, bons exemplos do direito comparado apontam no caminho de criar-se não tribunais especializados, pelo menos secções especializadas nas matérias da responsabilidade médica. Assim se passa na Alemanha, onde a maior parte dos Landgerichte têm câmaras especializadas para estes processos, embora apenas para causas cujo pedido seja superior a $€ 5.000 .^{14}$

Este ramo do Direito visa criar confiança nos operadores desta relação e promover o sentido de proximidade existencial e de regulação justa da relação de cuidado-perigo que é amplificada perante a vulnerabilidade do paciente.

Se afirmamos a autonomia sistêmica do Direito da Saúde, então - no plano metodológico - deve seguir-se a construção de regras hermenêuticas próprias. Assim, podemos enunciar dois princípios de interpretação em Direito da Saúde:

a) O princípio da não lesão de direitos fundamentais do doente, salvo fundamentação bastante. Assim tem sido defendida a ultima ratio da esterilização compulsiva de doentes mentais profundos; ${ }^{15}$ e do mesmo jeito a lei aponta para a ultima ratio do internamento compulsivo de doentes mentais. Num caso, como noutros - e de meros exemplos se trata -, visa-se o respeito pelo direito à integridade física e psíquica (art. 25.๑), o direito a constituir família (art. 36. CRP) e o direito à liberdade (art. 27.), cuja limitação deve estar sempre sob o manto do princípio da proporcionalidade (art. 18. ${ }^{\circ} \mathrm{CRP}$ ).

b) O princípio da validade e eficácia das normas profissionais e das regras deontológicas - expressamente afirmado pelo art. $4 .{ }^{\circ}$ da Convenção de Oviedo - e que se reveste com uma extrema utilidade em sede de integração de lacunas. É sabido que a natureza dúctil e densa da Deontologia médica permite dimensões de normatividade mais apuradas e mais finas do que a lei que se quer geral e abstrata.

c) O princípio da precaução nos avanços terapêuticos, que tem relevo metodológico, na medida em que uma intervenção que se desvie dos standards, maxime a utilização off-label de medicamentos, no âmbito das inovações terapêuticas e da

\footnotetext{
${ }^{14} \mathrm{~A}$ criação de tribunais especializados é também defendida pelo estudo da JOINT STATE GOVERNMENT COMMISSION -PENNSYLVANIA, Medical Professional Liability: Reform for the 21 ${ }^{\text {st }}$ Century: A Review of Policy Options, Pennsylvania, March 2005, p. 93 ss.: "The possible advantages of a specialized medical liability court include expertise, speed, and uniformity and coherence of outcomes."

15 Parecer 35/CNECV/01, sobre Laqueação de Trompas em Menores com deficiência Mental Profunda (3 de Abril de 2001)
} 
experimentação humana deve ser devidamente fundamentada e deve carecer de um controle procedimental justo, emergindo um paradigma procedimentalista (29).

d) O princípio do controlo procedimental na decisão bioética é outro dos vetores metodológicos marcantes do Direito da Saúde. Este controlo é defendido em muitas áreas sensíveis da medicina e recai sobre novas instituições, com competências multidisciplinares e com independência face ao poder político. Tal acontece porque frequentemente vezes o legislador reconhece a sua inabilidade para decidir questões controversas, sem apoios técnicos e éticos. Também se evidência que o poder judiciário tem sido um ator esquecido no Direito português, uma vez que raramente a lei remete para os tribunais a resolução de casos concretos, antes cria novas instituições de controlo e regulação.

Várias são as entidades que contribuem para uma decisão ética e jurídica mais próxima dos problemas concretos e constituídas por especialistas do foro jurídico, médico e científico, com vista a uma decisão mediada por um debate que vai desenvolvendo argumentos no sentido da legitimação da solução perante um dado auditório e perante a sociedade.

i. Para além do papel do Conselho Nacional de Ética para as Ciências da Vida e os contributos que tem tido no debate sobre a legislação que se vai produzindo sobre assuntos do biodireito, podemos destacar outras entidades com uma função de equilíbrio e debate no auditório da discussão bioética. ${ }^{16}$

ii. Assim acontece com o CNPMA que tem várias competências, algumas das quais muito polémicas, como por exemplo, g) Apreciar, aprovando ou rejeitando, os projetos de investigação que envolvam embriões entre as quais o polémico controlo do diagnóstico pré-implantação e a investigação com embriões; ou q) deliberar caso a caso sobre a utilização das técnicas de PMA para seleção de grupo HLA compatível para efeitos de tratamento de doença grave e, desde agosto de 2016, para autorizar e acompanhar um processo de gestação de substituição.

\footnotetext{
16 No domínio da proteção do bem-estar animal, a Diretiva 2010/63/UE do Parlamento Europeu e do Conselho de 22 de setembro de 2010 relativa à proteção dos animais utilizados para fins científicos vem impor a criação de um Comité Nacional para a proteção dos animais, bem como de uma rede de Comités locais a funcionar junto das instituições de investigação.
} 


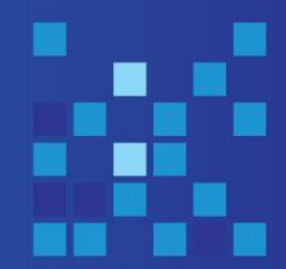

iii. Por seu turno, o Conselho Nacional de Saúde Mental controla a realização de intervenções de psicocirurgia. ${ }^{17}$

iv. As Comissões Técnicas de Certificação da Interrupção da Gravidez $^{18}$ criam as guidelines sobre quais as graves doenças ou malformações podem justificar a interrupção da gravidez em caso de fetopatia. ${ }^{19}$

v. Já a Comissão de Ética para a Investigação Clínica tem por principal função dar parecer vinculativo sobre a aceitabilidade ética de um ensaio clínico de medicamento para uso humano.

vi. As Comissões de Ética para a Saúde que podem coadjuvar na resolução de conflitos ético-jurídicos particulares na instituição em que estão sediadas.

vii. A Entidade de Verificação da Admissibilidade da Colheita para Transplante (EVA) é o organismo a quem cabe a emissão de parecer vinculativo em caso de dádiva e colheita em vida de órgãos, tecidos ou células para fins terapêuticos ou de transplante. ${ }^{20}$

Finalmente, este subsistema do Direito da Medicina poderia merecer - de jure condendo - uma reforma da Organização Judiciária. ${ }^{21}$

Em alguns países tem-se sugerido a criação de tribunais (rectius de para-tribunais) especializados para a resolução de problemas de responsabilidade civil médica.

\footnotetext{
17 Art. $5 .^{\circ}$, n. ${ }^{\circ} 2$ LSM: "A realização de intervenção psico-cirúrgica exige, além do prévio consentimento escrito, o parecer escrito favorável de dois médicos psiquiatras designados pelo Conselho Nacional de Saúde Mental".

18 Criadas pela Portaria n. 0 189/98, de 21 de março, e reguladas atualmente pela Portaria $\mathrm{n} . .-0741-\mathrm{A} / 2007$.

19 Cf. art. 142. ${ }^{\circ}, 2$, al. c) CP: "Houver seguros motivos para prever que o nascituro virá a sofrer, de forma incurável, de grave doença ou malformação congénita, e for realizada nas primeiras 24 semanas de gravidez, excepcionando-se as situações de fetos inviáveis, caso em que a interrupção poderá ser praticada a todo o tempo."

20 Art. 6.--A da Lei n. ${ }^{\circ} 22 / 2007$, de 29 de junho. A EVA é criada, em cada estabelecimento hospitalar onde se realize a colheita, por despacho do Ministro da Saúde, sob proposta conjunta do respectivo conselho de administração e da Organização Portuguesa de Transplantação. A EVA funciona na dependência e como secção da Comissão de Ética para a Saúde do estabelecimento hospitalar onde se realize a colheita.

21 Já em 1966, Fernando OLIVEIRA e SÁ, Acerca da Responsabilidade Profissional em Medicina, O Médico, n. ${ }^{\circ} 753,1966$, p. 11 defendia que a "responsabilidade médica, por usa natureza, pede assembleias específicas." O Autor avançava a proposta de "um colégio de médicos onde tivesse assento um jurista especialmente preparado para essa missão (...) Tal colégio seriam uma "primeira instância" obrigatória dos casos envolvendo responsabilidade em matéria médica. Aí se faria uma análise seletiva dos casos e se daria ou não daria andamento para os tribunais consoante fosse ou não fosse caso disso," dependendo da verificação de "imprevidência, imperícia ou negligência" ou não.
} 
Assinale-se como positivo que a Lei $n .0$ 44/2005, 29 de agosto (Lei das Associações de Defesa dos Utentes de Saúde) tenha conferido legitimidade processual às associações de utentes para representar interesses coletivos na área do direito da saúde.

Por outro lado, somos de parecer que o Ministério Público poderia criar um departamento que se ocupasse de forma mais especializada das violações dos direitos dos pacientes e com vista à tutela dos incapazes (em especial os menores e adultos incapazes de facto), em ordem à promoção e defesa dos seus direitos de cidadania na saúde.

Entre outras matérias, o Ministério Público poderia ser muito mais interventivo ao nível do controlo abstrato (ação inibitória) dos formulários para o consentimento informado, ao abrigo da Lei das Cláusulas Contratuais Gerais (art. 25. e 26.․ n.. 1, al. c), do DecretoLei $n .$. 446/85, de 25 de outubro) (30). Em segundo lugar, poderia o MP ser o verdadeiro protetor do cidadão incapaz, designadamente o cidadão doente em estado de incapacidade de facto (sem um tutor designado).

De jure condito apenas podemos assinalar - mas já com relevo notável e cumprindo a função de sublimação das pulsões de conflito jurídico existentes entre doentes e profissionais de saúde - a criação e o funcionamento dos Gabinetes do Utente, os quais permitem que o doente confronte o médico com o seu desagrado e que este processo é conhecido do Diretor de serviço e por vezes do próprio Conselho de Administração do Hospital. Esta prestação de contas, esta justificação do sucedido é, muitas vezes, suficiente satisfação para o doente lesado, com isso evitando querelas em tribunais que seriam bem mais dispendiosas e de consequências negativas para a confiança que urge criar na relação terapêutica e no mundo hospitalar!

Concluindo esta reflexão inicial, lembramos que: "Quem leve a sério a noção de direitos humanos é obrigado a aceitar a ideia vaga, mas poderosa, de dignidade humana" (27). A significar, com Kant, que o Homem tem que ser tratado como sujeito e não como objeto, como fim e não como meio.

Com base nesta ideia a que se opõe, entre outras, a de humilhação, a de instrumentalização, a de reificação, tem o Direito da Medicina erguido alicerces e construído edifícios - sempre polémicos, sempre conflituais - seja na interrupção voluntária da gravidez, seja no conceito de morte cerebral, na colheita de órgãos e tecidos post mortem para transplante ou na experimentação não terapêutica em crianças; seja na compensação por erro médico, ou no acesso ao processo clínico - mas sempre se deverá 


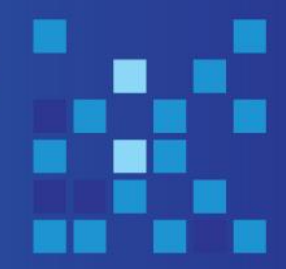

guiar pelos referentes fundamentais: criar confiança (Guilherme de Oliveira) ou, dito de modo diferente, reforçar a hospitalidade da medicina (Faria Costa) e promover a solidariedade existencial na relação de cuidado-perigo a que os profissionais de saúde estão vinculados face às pessoas doentes (31).

É que "curar" - seguimos Faria Costa - "é lutar contra "Atropos"; é fazer com que esta terrível deusa chegue mais tarde a cortar o fio da vida. Curar tem na sua raiz a dimensão de afirmação da vida. Da afirmação da luta perene entre Eros e Thanatos" (32).

E para curar bem - dentro de uma normatividade justa de promoção da cidadania e dos direitos humanos no âmago mesmo da atividade médica - precisamos de um Direito da Medicina cidadão (33) dialético e transformador. Pois como bem afirmou Sampaio: "afinal a medicina é feita para servir o homem, e não o inverso... ora é isto que, afinal, a noção de dignidade humana nos ajuda".

Concluindo com Orlando de Carvalho:

"Ouso sugerir: em nome do próprio projeto, dado que este, como atrás se insinuou, se inscreve em certo tempo e em certa civilização, tem de assumir, como ideal dinâmico, "o máximo de consciência possível", o máximo de emancipação humana, ou, como escreveu Maritain, a "conquista horizontal da liberdade, a "liberté d'épanouissement - que eu gosto de traduzir, e não só por preferência botânica, por liberdade de desabrochar" (34).

Ora, é este livre desabrochar que permite reconhecer a pessoa doente como alguém ainda em busca do desenvolvimento da sua personalidade e na construção da sua história pessoal, escrevendo a sua biografia. Esse deve ser o desígnio fundamental do Direito da Saúde.

Para alcançar este desiderato, de zelar pela dignidade da pessoa humana, importa construir um pensamento jurídico estruturado, com formação dogmática e histórica, com capacidade de diálogo interdisciplinar, que permita o desenvolvimento do Direito da Saúde, o que assume especial relevância no Século XXI, com a carência de água, com a hiperpopulação e a urbanização crescente da vida em sociedade.

\section{Referências}

1. Deutsch,E; Spickhoff A, Medizinrecht, Arzneimittelrecht, Medizinprodukterecht und Transfusionsrecht, 6. Auflage, Springer, 2008, p. 5. 
2. Rueff, C, O Segredo Médico como Garantia de Não-Discriminação, Estudo de Caso: HIV/SIDA, Coimbra, Coimbra Editora, 2009.

3. Loureiro, J, Aegrotationis medicinam ab iure peto? Notas sobre a saúde, a doença e o direito, Cadernos de Bioética 11 (2001/25): 19-53.

4. Kennedy, I; Grubb, A. Medical Law, Butterwoths, 2000

5. Correia,S. Introdução ao Direito da Saúde, Direito da Saúde e Bioética, Lisboa, 1991,

6. Loureiro,J. Transplantações: Um Olhar Constitucional, Coimbra, Coimbra Editora, 1995, p. 16.

7. Genicot, G. Droit médical et biomédical. Bruxelles: Larcier, 2010,

8. Loureiro, JC. Da sociedade técnica de massas à sociedade de risco: prevenção, e tecnociência. Algumas questões juspublicísticas". In Estudos em homenagem ao Prof. Doutor Rogério Soares, Coimbra, 2001, p. 797-891

9. Loureiro, JC. Bios, tempo (s) e mundo (s): algumas reflexões sobre valores, interesses e riscos no campo biomédico", in: Manuel da Costa Andrade, Maria João Antunes e Susana Aires de Sousa (Org.). Estudos em homenagem ao Prof. Doutor Jorge de Figueiredo Dias, vol. IV, Coimbra, 2010.

10. Herring, J. Medical Law and Ethics. Oxford: Oxford University Press, 2010

11. Loureiro, J. Em busca de um direito da saúde em tempos de risco (s) e cuidado (s): sobre a incerteza do (s) nome(s) e da(s) coisa(s). Direito da Saúde I - Objeto, Redes e Sujeitos. In Estudos de Homenagem ao Prof. Doutor Guilherme de Oliveira, Coimbra, Almedina, 2016.

12. Spickhoff, D. Medizinrecht 6, 2008

13. Mello, HP. Implicações Jurídicas do Projecto do Genoma Humano, Constituirá a Discriminação Genética uma Nova Forma de Apartheid, vol. I, Serviço de Bioética e Ética Médica da Faculdade de Medicina do Porto, 2007, Manual de Biodireito, Coimbra, Almedina, 2008.

14. Oliveira A. O Direito Civil como o Direito Comum do Homem Comum. Revista do Instituto do Direito Brasileiro da Faculdade de Direito da Universidade de Lisboa - RIDB, 1(1): 54,2012 .

15. Will, JF A brief history and theoretical perspective on patient and medical decision making: Part II: The autonomy model. Chest 139:1491-7. 2011.

16.Vilaça Ramos, H. Ars Medica, Técnica e Ética. Ação Médica, 2: 30-32, 2011. 
17. Taupitz, J. Die Standesordnungen der freien Berufe. New York: Gottingen, Gruyter, 1991.

18. Oliveira, G. A Auto-regulação profissional dos médicos, RLJ, Ano 134, jun,2001

19. Hart, D. Patients' Rights and Patients' Participation Individual and Collective Involvement: Partnership and Participation in Health Law., EJHL, 11, 2004

20. Cunha, P. "Do Código Civil (Meditações sobre a lei mais importante do País)", O Direito, Ano 98, 1966, p. 315.

21. Monteiro, AJP. Sobre o Direito do Consumidor em Portugal e o Anteprojecto do Código do Consumidor. Coimbra, 2005.

22. Neves, MCP. Article 8: Respect for Human Vulnerability and Personal Integrity. In Michèle S. Jean (coord.), The UNESCO Universal Declaration on Bioethics and Human Rights. Background, principles and application, Paris, UNESCO, 2009.

23. Bobbio, N. A Era dos Direitos, São Paulo: Martin Claret, 2002.

24. Santos, BS. Por uma sociologia das ausências e uma sociologia das emergências. Revista Crítica de Ciências Sociais, 63:237-280, out. 2002.

25. Canotilho, JG; Moreira, V. Constituição da República Portuguesa Anotada, Coimbra: Coimbra Editora, 2007.

26. Silva Neto, MLA. Novos Direitos ou Novo(s) objecto(s) para o Direito. Porto: Universidade do Porto Editora, 2010.

27. Dworkin, R.Taking Rights Seriously. Boston: Harvard University Press, 1978.

28. Weide, U. Law and the German Universal Healthcare System: a Contemporary Overview. German Law Journal, 6 :1143. 2005.

29. Sargos, P.Approche judiciaire du principe de précaution en matière de relation médecin/patient,.La Semanie Juridique Édition Générale JCP, 2000.

30. Pereira, AD. Novos Desafios da Responsabilidade Médica: uma proposta para o Ministério Público. Direito e Sociedade - Revista do Ministério Público do Estado do Paraná, 3 (2):35-58.

31. Sampaio, J. O Alfa e o Ômega: a vida e a morte e os mitos do eterno retorno - uma perspectiva da aliança das civilizações. In: José Faria Costa e Inês Fernandes Godinho (orgs.) As Novas Questões em Torno da Vida e da Morte em Direito Penal. Coimbra: Coimbra Editora, 2011. 
32. Faria Costa, J. Bioética e Direito Penal (Reflexões possíveis em tempos de incerteza). in: Ars Ivdicandi. Estudos em Homenagem ao Prof. Doutor Jorge de Figueiredo Dias, v. I, BFD, Coimbra, 2009.

33. Pitcho, B. Le statut juridique du patient, Bordeaux: Les Études Hospitalières, 2004.

34. Carvalho, O. Para um Novo Paradigma Interpretativo: o Projecto Social Global, Casa da Relação do Porto, 1995.

Recebido em: 19/9/2016

Aprovado em: 29/9/2016

\section{Como citar este artigo:}

Pereira AGD. A emergência do direito da saúde. Revista Cadernos Ibero-Americanos de Direito Sanitário. 2016 jul./set, 5(2):180-200. 